\section{Seal echolocation?}

THE evidence reported by Renouf and Davis ${ }^{1}$ for echolocation by a 7 -yr-old male harbour seal (Phoca vitulina) is not convincing enough to require a reassessment of earlier studies ${ }^{2-5}$ which found no experimental evidence for echolocation in pinnipeds.

The ability of the seal to swim across the $7.5 \mathrm{~m}$ diameter tank and locate a ring in the dark does not in itself indicate an echolocation ability. In field tests one of us (N. Sonafrank, R. Elsner and D.W., in preparation) has demonstrated the ability of a blindfolded spotted seal (Phoca vitulina largha) to find and surface through a $50-\mathrm{cm}$ diameter hole in the ice from a starting hole over $30 \mathrm{~m}$ away. The seal produced no vocalizations during this sub-ice swimming and was equally successful in the presence of high levels of white background noise. Moreover, Oliver ${ }^{4}$ found a negative correlation between sound emission and improved navigational ability by a 3-yr-old male grey seal (Halichoerus grypus) swimming through different obstacle courses in the dark.

There are several problems with the experimental design of Renouf and Davis' ring discrimination experiment. First, even though the rings are visually identical, the dynamics of motion in the water of the weighted, air-filled ring will be quite different from that of the weighted, waterfilled ring. Thus, the animal could discriminate between the rings visually by observing this motion in response to a pressure wave generated by the animal's swimming.

Since the majority of the experimental sessions (8-26) were conducted in the light and since the experimenter holding the targets by means of strings knew which one was the air-filled correct choice, the investigators have failed to rule out the possibility that they provided the animal with inadvertent cues. Finally, during the control sessions when both rings were water-filled, the learning curve, as indicated by the discrimination ratio in Fig. 2 of Renouf and Davis ${ }^{1}$, is improving at a rate equal to or greater than that of the initial learning with the acoustically different rings during the experimental phase. Since the learning curve in the control situation had shown no sign of an asymptote, we cannot understand why the control phase was terminated after only 5 sessions compared with the 26 sessions of the previous experimental phase. We therefore find no justification for the conclusion that this was an adequate control test to confirm the previously demonstrated discrimination.

In a long-term study of vocalizations of spotted seals, we ${ }^{6}$ have recorded pulses similar to those reported by Renouf and Davis ${ }^{1}$, although pulse trains were more common than single or double pulses. We find that a major change in frequency of occurrence of the pulse trains occurs on an annual cycle, peaking during the breeding seasons during the $6 \mathrm{yr}$ we have monitored these vocalizations. The field recordings by Renouf and Davis ${ }^{1}$ were from a breeding colony, although they did not indicate the time of the year at which the recordings were made.

\section{DOUGLAS WARTZOK}

Purdue University,

Fort Wayne, Indiana 46805, USA

RONALD J. SCHUSTERMAN

California State University,

Hayward, California 94542, USA

JANET GAILEY-PHIPPS

Johns Hopkins University,

Baltimore, Maryland 21205, USA

1. Renouf, D. \& Davis, M. B. Nature 300, 635-637 (1982) 2. Evans, W. \& Haugan, R. Bull. Sth Calif. Acad. Sci. 62 , 165-175 (1963).

3. Schusterman, R. J. in Animal Sonar Systems: Biology and Bionics (ed. Busnel, R.) 535-617 (Laboratoire de Physiologie Acoustique, Jouyen-Josas, France, 1967).

4. Oliver, G. W. Behaviour 67, 97-114 (1978).

5. Scronce, B. \& Ridgway, S. in Animal Sonar Systems (eds Busnel, R. \& Fish, J.) 991-993 (Plenum, London, 1980). 6. Wartzok, D., Gailey-Phipps, J., Schultz, N. \& Beier, J. C. Proc. 4th bien. Conf. Biol. of Marine Mammals, 122 (University of California, Santa Cruz, 1981).

RENOUF REPLIES - I agree with Wartzok et al. that our study does not necessarily require the reassessment of those which failed to demonstrate echolocation. There is no reason to assume that what might be true for harbour seals would also hold for Halichoerus, Zalophus or Pivi Pargha, although the reverse logic should not be expounded either. My major concern was the fact that those interested in pinniped sensory function were tacitly 'accepting the null hypothesis' and concluding from negative evidence that seals do not use sonar.

I agree with most of the reservations expressed by Wartzok et al. about the study ${ }^{1}$ and in fact alluded to many of them in the discussion. The discrimination ratios or the control tests were from 0.35 to 0.50 which Wartzok et al. feel is a significant trend. Apart from the fact that this difference did not prove to be statistically significant, a change in behaviour from mostly incorrect $(0.35)$ to random $(0.50)$ is not the same as the improvement shown by the seal during discrimination training from 0.63 to criterion. The problem of differential hydrodynamic motion of the rings occurred to me and was one of the reasons I switched to running in daylight. I wanted to make sure that the seal did not move both rings before making his decision. When we could see what was going on, we immediately released the first ring the animal touched as his choice. As far as we could tell, his swimming did not cause any ring motion (I assume Wartzok et al. meant displacement wave rather than presure wave generated by the seal's movement) - which is not to say that what we could not detect that the seal could not. The other problem I still have is the relative paucity and quiet of the clicks the seal made during the discrimination. I postulated in the report ${ }^{1}$ that perhaps this was his best solution to boundary reverberation. Since then I have replicated the study with the rings suspended in the middle of the tank. The seal's discrimination ratio improved to 0.90 ; however, the clicks were still few and faint, but increased in peak energy to $21 \mathrm{kHz}$. The main difficulty is working in a relatively small tank where boundary reverberations are problematical. The vocalizations from the captive seals are weak compared with those I have obtained in the field, and so I am hoping to resolve this by building an ocean pen.

DEANE RENOUF

Department of Psychology, Memorial University of Newfoundland, St John's, Newfoundland,

Canada A1B $3 X 9$

1. Renouf, D. \& Davis, M. B. Nature 300, 635-637 (1982).

\section{DNA-binding proteins}

IN a recent News and Views article ${ }^{1}$, Andrew Travers states that in a eukaryote '... a [specific] DNA-binding protein must have $10^{2}-10^{3}$-fold higher affinity for its binding site than would be necessary in Escherichia coli... and that to achieve efficient occupancy the sequence specificity of the interaction relative to random binding must be $10^{3}$ times greater than that [of specific DNA-binding proteins found in $E$. coli]'. Travers' conclusion is not true. In fact, based on what we know about two prokaryotic gene regulators, the $l a c$ and $\lambda$ repressors, we expect that each would bind to its single specific operator equally efficiently whether that operator were in a bacterium or in a mammalian cell, provided that the concentration of the protein in the mammalian nucleus equalled that found in the bacterial nucleoid body. (The two prokaryotic repressors use somewhat different strategies to efficiently bind operator: $\lambda$ repressor has lower affinities for operator and for random DNA than does lac repressor and, unlike the latter, it binds cooperatively to adjacent DNA sites. A bacterium typically contains about 10 20 lac repressors and the equivalent of about 100 dimers, the active species ${ }^{2}$.

Travers evidently believes that his conclusions follow from the facts that '.. in a mammalian nucleus the concentration of a unique DNA-binding site [operator] is about $10^{2}$ times per genome lower than in $E$. coli while the potential number of random DNA-binding sites is $10^{3}-10^{4}$ times greater'. But the important factor is the concentration of repressor free to interact with operator, a quantity determined by the total repressor concentration and, in some cases, by the concentration of nonspecific DNA. Both $\lambda$ and lac repressors, for example, have measurable affinities for nonspecific DNA and, especially in the latter case,-this effectively decreases the free repressor concentration in a bacterium ${ }^{3,4}$. The important point in the present context is that, according to Lin and Riggs, the total DNA concentration, and hence the concentration of nonspecific binding sites, is roughly the same in a mammalian cell nucleus and in a 